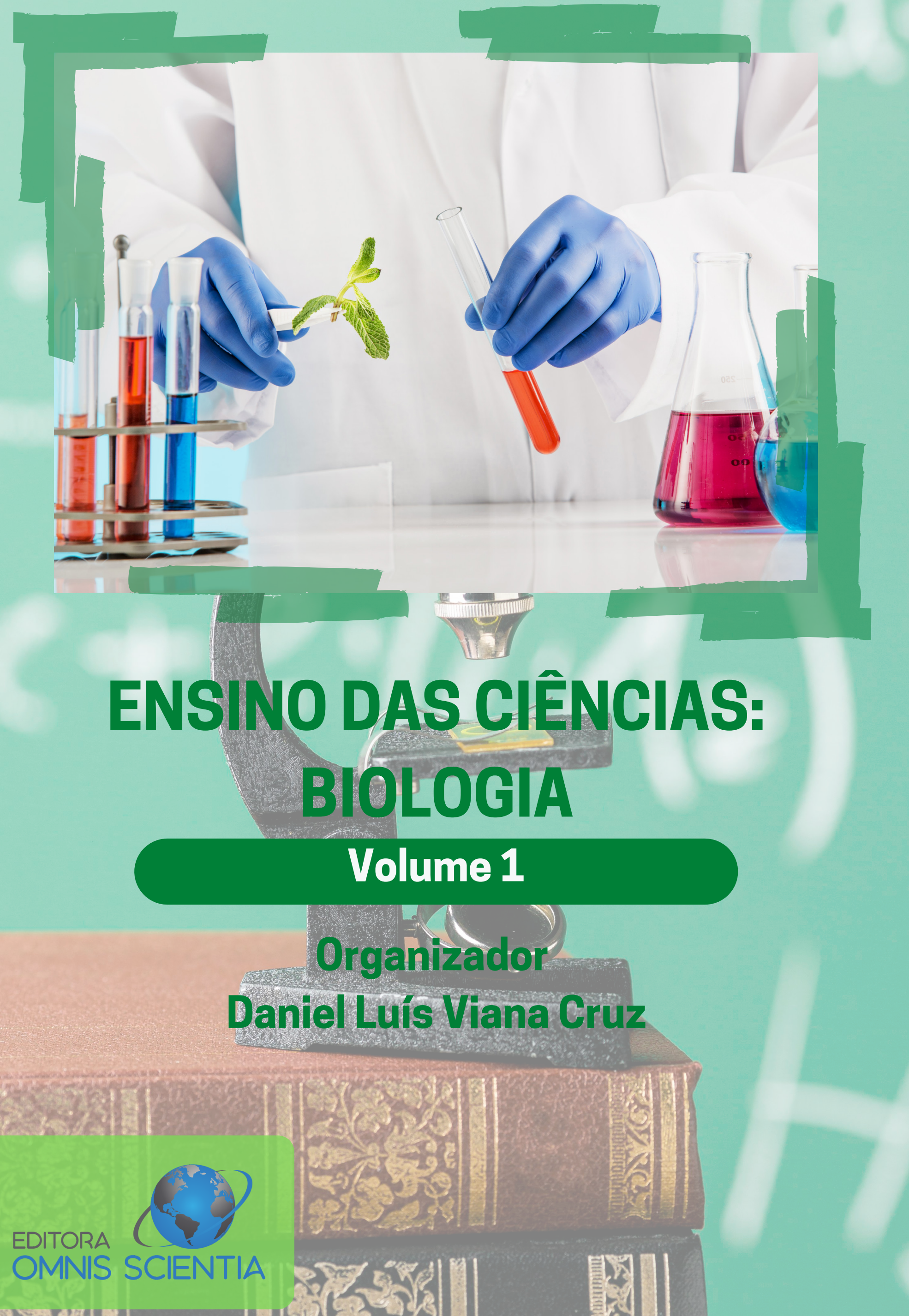




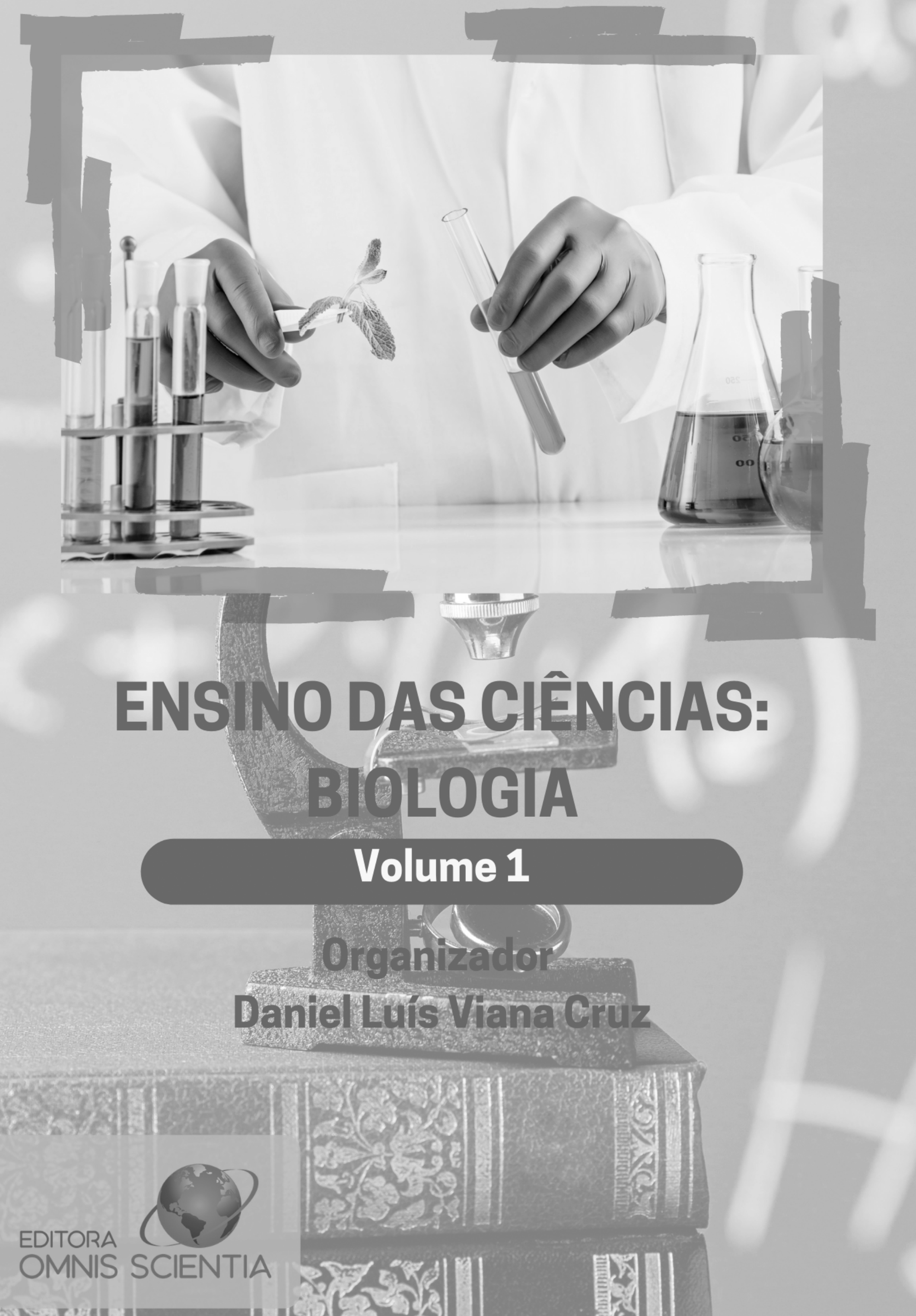


Editora Omnis Scientia

\section{ENSINO DAS CIÊNCIAS: BIOLOGIA}

Volume 1

$1^{\mathrm{a}}$ Edição

TRIUNFO - PE 


\section{Editor-Chefe}

Me. Daniel Luís Viana Cruz

Organizador (a)

Me. Daniel Luís Viana Cruz

\section{Conselho Editorial}

Dra. Pauliana Valéria Machado Galvão

Dr. Wendel José Teles Pontes

Dr. Walter Santos Evangelista Júnior

Dr. Cássio Brancaleone

Dr. Plínio Pereira Gomes Júnior

Editores de Área - Ciências Humanas

Dr. Cássio Brancaleone

Dr. José Edvânio da Silva

Assistentes Editoriais

Thialla Larangeira Amorim

Andrea Telino Gomes

Imagem de Capa

Freepik

\section{Edição de Arte}

Leandro José Dionísio

Revisão

Os autores

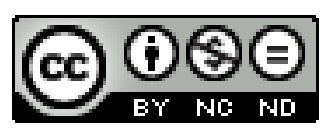

Este trabalho está licenciado com uma Licença Creative Commons - AtribuiçãoNãoComercial-SemDerivações 4.0 Internacional.

O conteúdo abordado nos artigos, seus dados em sua forma, correção e confiabilidade são de responsabilidade exclusiva dos autores. 


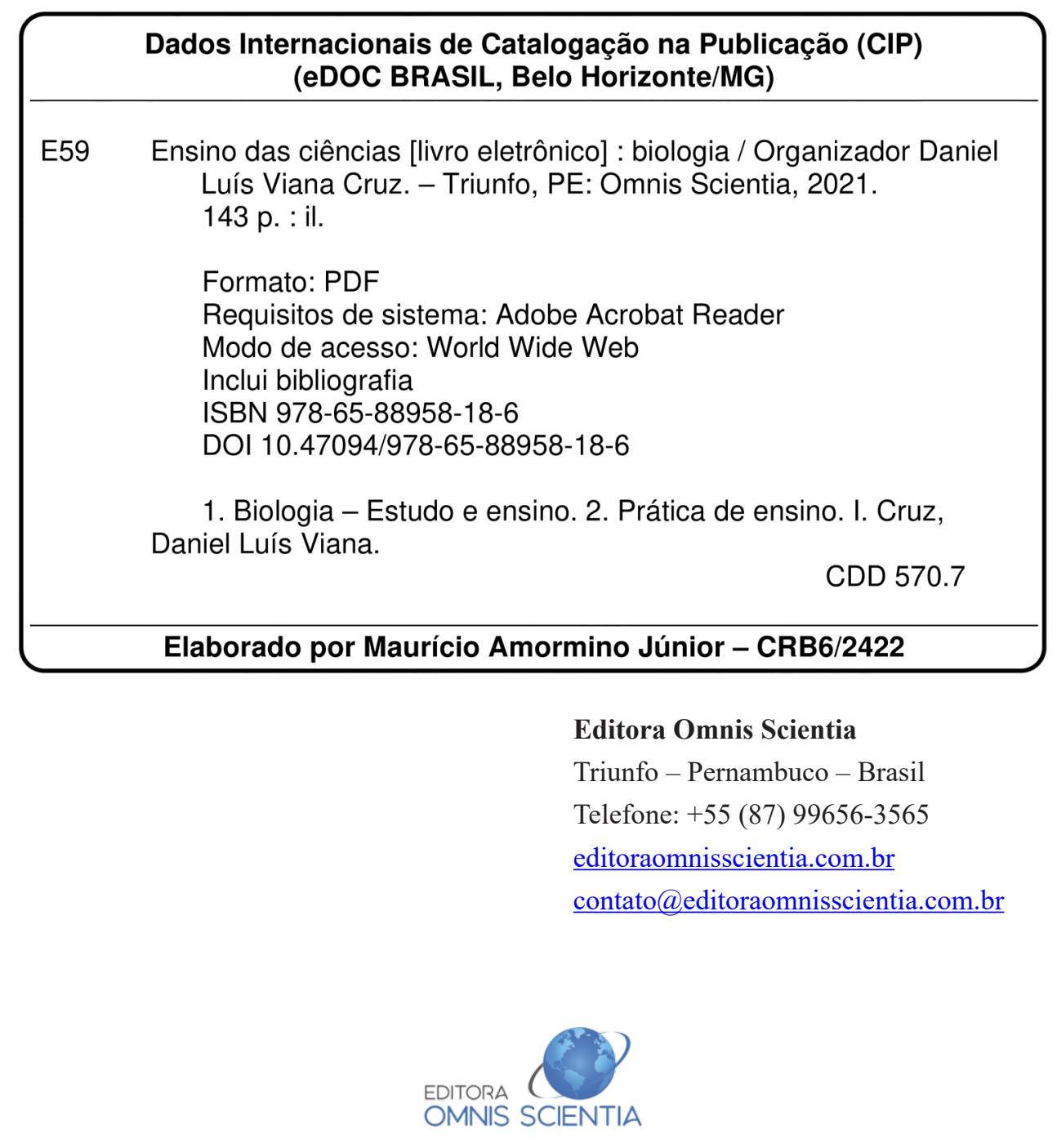




\section{PREFÁCIO}

O ensino é mais do que uma vocação, no país que vivemos trata-se de um sacerdócio. Ensinar, com poucos recursos e sem o merecido reconhecimento por parte da sociedade é persistir numa luta sem fim. Principalmente nesse período obscurecido pela desinformação e pelo negacionismo. Mas quando falamos de ensinar ciências, isso se torna ainda mais complexo, pois poucas escolas, sejam elas públicas ou privadas, possuem infraestrutura para aulas práticas. Que são tão importantes na fixação da informação. E assim os professores das ciências (Matemática, Física, Química e Biologia) seguem fazendo "mágica" nas salas de aula para que os alunos aprendam o mínimo necessário para a vida. Quando se trata de ensina Biologia, há muito que fazer com poucos recursos e o mínimo de boa vontade. E nessa obra o leitor poderá se inspirar em metodologias e ideias muito interessantes publicadas pelos autores.

Em nossos livros selecionamos um dos capítulos para premiação como forma de incentivo para os autores, e entre os excelentes trabalhos selecionados para compor este livro, o premiado foi o capítulo 3, intitulado "UM OLHAR PARA O ENFRENTAMENTO DAS VISÕES INGÊNUAS SOBRE A CIÊNCIA NO ENSINO DE BIOLOGIA”. 


\section{SUMÁRIO}

CAPÍTULO 1

AULAS REMOTAS DE CIÊNCIAS E BIOLOGIA DURANTE A PANDEMIA DO COVID-19 NA PERSPECTIVA DOS DISCENTES

Priscila Chaves de Souza

Hélio da Guia Alves Junior

DOI: $10.47094 / 978-65-88958-18-6 / 11-18$

CAPÍTULO 2 19

PRODUÇÃO E UTILIZAÇÃO DE MATERIAIS DIDÁTICOS NO ENSINO - APRENDIZAGEM DE DOENÇAS PARASITÁRIAS COMO: AMEBÍASE.

Sarah Lorena Silva Santos

Talessa Viegas Araujo

Samara Alves Correa

Lara Vitória Ribeiro Ferreia

Suelen Rocha Botão Ferreira

Lise Maria Mendes Holanda de Melo Ferreira

DOI: 10.47094/978-65-88958-18-6/19-27

CAPÍTULO 3 .28

UM OLHAR PARA O ENFRENTAMENTO DAS VISÕES INGÊNUAS SOBRE A CIÊNCIA NO ENSINO DE BIOLOGIA

Elda Cristina Carneiro da Silva;

Joanez Aparecida Aires

DOI: 10.47094/978-65-88958-18-6/28-41 
CAPÍTULO 4

ABORDAGEM DO TEMA SISTEMAS DE ENTREGA DE FÁRMACOS NO ENSINO FUNDAMENTAL

Edmilson Clarindo de Siqueira

José Adonias Alves de França

Silvana Caroline de Holanda

DOI: $10.47094 / 978-65-88958-18-6 / 42-52$

CAPÍTULO 5

A NANOTECNOLOGIA APLICADA AO ENSINO DE CIÊNCIAS

Edmilson Clarindo de Siqueira

José Adonias Alves de França

Silvana Caroline de Holanda

Fábio Rocha Formiga

DOI: $10.47094 / 978-65-88958-18-6 / 53-64$

CAPÍTULO 6 .65

OFICINAS DE CORDEL COM TEMAS DE BIOLOGIA

Edmilson Clarindo de Siqueira

José Adonias Alves de França

Silvana Caroline de Holanda

DOI: $10.47094 / 978-65-88958-18-6 / 65-75$

CAPÍTULO 7.

RELAÇÃO HOMEM E NATUREZA NAS MARGENS DO RIO PERICUMÃ NA CIDADE DE PINHEIRO-MA

Gabrielly Soares Dias Gonçalves 
Jenilce Monica Ferreira Fernandes

Werberth Braga Bastos

Hellen José Daiane Alves Reis

DOI: $10.47094 / 978-65-88958-18-6 / 76-86$

CAPÍTULO 8 .87

METODOLOGIAS ATIVAS NO ENSINO DE FISIOLOGIAHUMANA: O OLHAR DOS FUTUROS PROFESSORES

Maria Iracema Barbosa Moura

Francisco de Assis Pereira da Silva

Helayne Barbosa Moura

DOI: 10.47094/978-65-88958-18-6/87-96

CAPÍTULO 9 97

CORRIDA DE ESPERMATOZOIDES: SEXO E HERANÇA - UMA PROPOSTA INTERATIVA PARA O ENSINO DE HEREDITARIEDADE

Fernanda Pacheco-Fernandes

Benn Richard Alle

Iris Hass

Luciane Viater Turek

Maíra Alexandre Peres

Lupe Furtado-Alle

DOI: $10.47094 / 978-65-88958-18-6 / 97-112$

CAPÍTULO 10 113

DANÇA DOS CROMOSSOMOS: USANDO A LUDICIDADE PARA ENSINAR HEREDITARIEDADE 
Fernanda Pacheco-Fernandes

Benn Richard Alle

Iris Hass

Luciane Viater Tureck

Maíra Alexandre Peres

Lupe Furtado-Alle

DOI: $10.47094 / 978-65-88958-18-6 / 113-126$

CAPÍTULO 1

A DiscuSSÃO DA HOMOSSEXUALIDADE EM UM LIVRO PARADIDÁTICO DE SEXUALIDADE

Lucas Mendes Silva

Vitoria Raquel Pereira de Souza

Jackson Ronie Sá-Silva

DOI: $10.47094 / 978-65-88958-18-6 / 127-137$ 


\title{
DANÇA DOS CROMOSSOMOS: USANDO A LUDICIDADE PARA ENSINAR HEREDITARIEDADE
}

\author{
Fernanda Pacheco-Fernandes ${ }^{1}$ \\ Universidade Federal do Paraná (UFPR), Curitiba, Paraná. \\ Lattes:https://wwws.cnpq.br/cvlattesweb/PKG_MENU.menu?f \\ cod=8AE46A9B28C89CD917AE0AF750F6CAC9\#
}

ORCID ID: https://orcid.org/0000-0001-8077-226X

\section{Benn Richard Alle ${ }^{2}$}

Universidade Federal do Paraná (UFPR), Curitiba, Paraná.

ORCID ID: https://orcid.org/0000-0001-7810-1002

\section{Iris Hass $^{3}$}

Universidade Federal do Paraná (UFPR), Curitiba, Paraná.

ORCID ID: https://orcid.org/0000-0003-4723-2178

\section{Luciane Viater Tureck ${ }^{4}$}

Universidade Federal do Paraná (UFPR), Curitiba, Paraná.

ORCID ID: https://orcid.org/0000-0002-4200-1189

\section{Maíra Alexandre Peres 5}

Universidade Federal do Paraná (UFPR), Curitiba, Paraná.

ORCID ID: https://orcid.org/0000-0003-2672-2389

\section{Lupe Furtado-Alle}

Universidade Federal do Paraná (UFPR), Curitiba, Paraná.

ORCID ID: https://orcid.org/0000-0002-1616-8225

RESUMO: As Leis de Mendel são base para a compreensão da hereditariedade, fenômeno biológico de extrema importância em diferentes contextos da biologia. O entendimento dos mecanismos biológicos subjacentes às Leis de Mendel, as quais muitas vezes são reduzidas a memorização de 
proporções matemáticas, depende da integração de conhecimentos da genética com a biologia celular, no entanto, a fragmentação de saberes e conteúdos de biologia dificulta essa integração, o que impacta diretamente na compreensão desse conteúdo por parte dos estudantes. Dessa forma, com o objetivo de disponibilizar ao professor de biologia uma ferramenta didática que estimule a compreensão da relação existente entre $1^{\mathrm{a}}$ e $2^{\mathrm{a}}$ Lei de Mendel e Ligação Gênica com a meiose, foi desenvolvida a "Dança dos Cromossomos", uma dinâmica que oportuniza uma linguagem diferente no processo de ensino e aprendizagem de biologia, na qual a inteligência cinestésico-corporal é mobilizada juntamente com a observação e a audição. Nessa dinâmica, os alunos atuam como cromossomos ou fusos meióticos, integrando nesse processo os princípios hereditários estabelecidos pelas Leis de Mendel com o comportamento dos cromossomos durante a formação dos gametas. Durante a realização dessa dinâmica, é necessário que o aluno mobilize o que foi trabalhado teoricamente e transforme em ação, estimulando assim a aplicação do conhecimento em diferentes linguagens, além de proporcionar a integração entre sujeitos a fim de compreender de forma integral e conectada os fenômenos biológicos que regem a hereditariedade.

PALAVRAS-CHAVE: hereditariedade. Leis de Mendel. Meiose.

\title{
CHROMOSOME DANCE: USING LUDICITY TO TEACH HEREDITARITY
}

\begin{abstract}
Mendel's laws are the basis for understanding heredity, a biological phenomenon of extreme importance in different biology contexts. The understanding of the biological mechanisms underlying Mendel's Laws, which are frequently reduced to memorization of mathematical proportions, depends on the integration of the genetics and cell biology knowledge, however, fragmentation of knowledge and contents of biology complicates this integration, which directly impacts students' understanding of this content. Thus, in order to make available to the biology teachers a didactic tool that facilitates the understanding of the relationship between Mendel's 1st and 2nd Law and Genetic Link with meiosis, the "Chromosome Dance" was developed. It consists in a dynamic that provides a different language in the teaching and learning scientific process, in which kinestheticcorporal intelligence is mobilized along with observation and hearing. In this dynamic, students act as chromosomes or meiotic spindles, integrating in this process the hereditary principles established by Mendel's Laws with the chromosomes behavior during the gametes genesis. During the realization of this dynamic, students have to mobilize what has been worked on theoretically and transform it into action, thus stimulating the application of this knowledge in different languages, in addition, this dynamic providing integration between subjects in order to fully understand the biological factors that govern heredity.
\end{abstract}

KEY WORDS: heredity; Mendel's Laws; meiosis. 


\section{INTRODUÇÃO}

Os conhecimentos de Genética no ensino médio, apesar de sua relevância, muitas vezes são abordados de forma superficial ou mesmo descontextualizada. Isso provavelmente seja em decorrência da dificuldade encontrada por alguns docentes em abordar assuntos abstratos para os estudantes ou até mesmo para eles próprios. Pois para que ocorra o processo de ensino-aprendizagem sobre como se dá o fenômeno biológico da hereditariedade, é necessário alcançar um nível de compreensão básico relacionado à ligação física entre genes e cromossomos. Consolidando esses conhecimentos previamente, será possível compreender processos biológicos, como os tipos de divisão celular e a fecundação. Para permitir, a partir disso, a compreensão da continuidade da informação genética nos organismos por meio da reprodução sexuada. Porém muitos desses conceitos são aprendidos separadamente, inclusive em séries diferentes, dificultando o estabelecimento de relações entre esses. Esperando-se que o professor em anos seguintes estabeleça essas relações, o que pode não ocorrer (LEWIS, et. al, 2000). O ensino de Genética no ensino médio, se dá de forma fragmentada e desconexa, um dos motivos pode ser a distribuição didática dos objetos do conhecimento. Como por exemplo, a divisão celular e as Leis de Mendel, pois os conceitos e processos de biologia celular são ensinados no $1^{\circ}$ ano do ensino médio e os conceitos básicos da hereditariedade, que necessitam da compreensão dos processos celulares para serem entendidos, são estudados apenas no $3^{\circ}$ ano do ensino médio. O que dificulta a compreensão da integração desses objetos de conhecimento para a compreensão do todo, sendo que na maioria das vezes, as associações entre esses diferentes tópicos, não ficam explicitas (MANZKE, 1999). Os capítulos introduzindo o assunto de genética em geral, iniciam-se com a biografia e os experimentos de Mendel, como se esse cientista estivesse isolado geograficamente e historicamente. Seus experimentos são explicados e já se iniciam os cruzamentos. Não se faz relação do processo celular envolvendo a produção de gametas e da fecundação, como se o estudante fosse resgatar por conta própria o conhecimento de séries anteriores. Alguns docentes às vezes também, por desconhecimento, ou por ater-se apenas ao material didático, muitas vezes não realiza essa retomada. $\mathrm{O}$ estudante chega a compreender matematicamente a probabilidade da formação dos descendentes, mas biologicamente não.

Para Justina e Rippel (2003) o entendimento dessas ideias poderia ser melhorado por meio de uma recapitulação da divisão celular e dos tipos celulares, em termos de produtos e informações genéticas que cada tipo produz. Estudos apontam que a disciplina de genética é de difícil compreensão até mesmo para alunos concluintes do ensino médio e que ingressaram em cursos de Biologia (WOODROBINSON et al., 2000). Acredita-se que essas dificuldades estejam relacionadas à clareza com que a disciplina é ministrada para que a aprendizagem possa ser significativa (CID e NETO, 2005). O entendimento da relação entre as células, cromossomos, genes, ácidos nucléicos e a relevância das proteínas dentro de um indivíduo é fundamental para uma compreensão de herança genética e das leis que regem a transmissão de algumas características.

Para que ocorra uma aprendizagem significativa, é importante a interação do novo conhecimento com os conhecimentos que os estudantes já possuem. Assim, o novo conhecimento ancora-se ao conhecimento prévio e passa a ter significado para aprendiz, tornando-se mais elaborado 
(AUSUBEL, 1965). No processo da aprendizagem significativa, o aprendiz não é um mero receptor passivo e sim participante ativo da construção do próprio conhecimento (MOREIRA, 2000).

O uso de atividades lúdicas em genética pode auxiliar o professor a despertar o interesse em seus estudantes por essa área de estudo, pois tornam sua compreensão mais acessível. A aula torna-se mais prazerosa e os alunos sentem-se motivados a participar e a se envolver (HERMANN e ARAÚJO, 2013). As atividades lúdicas aproximam os estudantes do conteúdo teórico, otimizando sua compreensão e reestabelecendo a aprendizagem significativa, uma vez que este se entusiasma e aprende de forma interativa e divertida (CAMPOS, et al, 2003).

Outro quesito importante de ressaltar, é que cada pessoa possui diferentes tipos de inteligências, sendo assim, cada indivíduo aprende de forma diferente e em ritmos distintos. A partir do conhecimento da Teoria das Inteligências Múltiplas de Howard Gardner (1995), é importante que os docentes busquem propostas de ensino-aprendizagem que visem a estimular os variados tipos de inteligências nas diferentes etapas do desenvolvimento humano. Sendo assim, as atividades lúdicas possuem o potencial de estimular estudantes com inteligência cinestésico-corporal ou inteligência espacial, por exemplo, além da inteligência interpessoal, por permitir interação com demais estudantes. Gardner (1995) considera que as Inteligências Múltiplas possuem várias facetas, como talentos, habilidades e capacidades mentais variadas e distintas em cada indivíduo.

Crianças e adolescentes possuem necessidades distintas e respondem a diferentes formas de informação cultural e assimilam conteúdos com diferentes estruturas motivacionais e cognitivas, logo os tipos de regimes educacionais planejados pelos educadores precisam levar em consideração esses fatores de desenvolvimento. Os tipos de modelos educacionais que são oferecidos durante o período escolar podem influenciar a direção que elas poderão tomar, podendo ser encorajadas ou impedidas de desenvolver certos tipos de habilidades ou expressar sua criatividade (TRAVASSOS, 2001).

A educação precisa ser modelada de forma a responder às diferenças mentais que existem entre os indivíduos. Deveria tentar garantir que cada pessoa recebesse uma educação que maximizasse seu potencial intelectual, pois os indivíduos dificilmente dominarão nem mesmo uma única área de conhecimentos, quanto mais toda a série de disciplinas e competências. Conhecendo a Teoria das Inteligências Múltiplas pode-se dizer que na escola a necessidade de repensar os objetivos e métodos educacionais torna-se profunda e que é importante desenvolver o pensamento lógico e a cognição em parceria com as demais dimensões humanas (TRAVASSOS, 2001).

Sendo assim, a partir da necessidade de propor aos professores de Biologia um meio de se realizar uma estratégia de ensino-aprendizagem que integre conceitos e fomente uma visão menos abstrata acerca dos processos biológicos, é apresentada uma proposta de atividade lúdica para estudantes do $3^{\circ}$ ano do Ensino Médio. Nessa atividade são integrados os processos que envolvem a meiose e os princípios hereditários estabelecidos pela $1^{\mathrm{a}}$ e $2^{\mathrm{a}}$ Lei de Mendel, além da Ligação Gênica. A estratégia foi denominada 'Dança dos Cromossomos', devido ao seu caráter de promover a movimentação dos estudantes. 


\section{METODOLOGIA}

O estudo é de caráter qualitativo e de natureza aplicada, uma vez que é uma proposta didática. $\mathrm{O}$ objetivo é descrever o relato de caso em que a atividade lúdica foi aplicada, além de expor a proposta, o material e os procedimentos passo a passo, para que outros professores tenham possibilidade de reproduzir a estratégia, caso julguem viável.

Quanto aos aspectos éticos, essa pesquisa foi apreciada junto ao Comitê de Ética e Pesquisa do Setor de Ciências da Saúde da Universidade Federal do Paraná, tendo parecer favorável de número 3.374.017.

Foi delineada para estudantes do ensino médio, mas também pode ser usada com estudantes de graduação e na formação de docentes.

\section{Materiais:}

- 8 folhas sulfite

- fita adesiva

- caneta hidrográfica

- 4 metros de barbante

\section{Etapas da dinâmica:}

\section{- $1^{a}$ Etapa: explorando a $1^{a}$ Lei de Mendel}

\section{$1^{\text {a }}$ Lei de Mendel e meiose}

A Primeira Lei de Mendel (lei da segregação) enuncia que cada caráter é determinado por um par de fatores que se separam na formação dos gametas, indo apenas um dos fatores para cada gameta. Atualmente, sabe-se que esses fatores representam os genes, cujos alelos aos pares determinam uma característica, quando tratamos de heranças monogênicas. E para que os estudantes compreendam a relação da Primeira Lei de Mendel com a meiose, sugerimos uma simulação em que os participantes representam os cromossomos. Os alelos são representados por uma folha sulfite colada ao corpo de cada participante, sendo que a célula em que esses processos estão ocorrendo é delimitada por um barbante colocado no chão de forma circular. Em substituição ao barbante, pode-se demarcar o limite da célula com risco de giz no chão. 


\section{Para a $1^{\text {a }}$ Lei de Mendel,}

- Inicialmente participam dois estudantes com uma folha sulfite com letras representando os alelos, nesse momento, apenas um par (Figura 1-I).

- Em seguida, os cromossomos são duplicados (Figura 1-II), o que é representado pela inserção de mais um estudante da turma. Os colegas devem ficar unidos de braços dados (representando os centrômeros), cada um correspondendo a uma cromátide irmã.

A partir daí representa-se a sequência de acontecimentos que compõem a meiose (meiose I e II), que deve ser narrada pelo professor desde sua preparação, que seria a interfase, até o final, para fazer com que os estudantes percebam a distribuição dos alelos que ocorre na formação dos gametas.

\section{Meiose I:}

- Na prófase I, ocorre a compactação dos cromossomos e o pareamento dos cromossomos homólogos (Figura 1 -III).

- Na próxima fase é a metáfase I, em que os pares de homólogos são alinhados na placa metafásica.

- Em seguida, dois outros alunos representam o fuso meiótico para puxar os cromossomos homólogos para lados opostos na célula (Figura 1-IV), correspondendo à anáfase I.

- A telófase I é apenas narrada, quanto à formação das membranas nucleares e à descondensação dos cromossomos, seguida da citocinese (Figura 1-V).

Então, inicia-se a meiose II.

- Na prófase II é narrada a condensação dos cromossomos duplicados e a fragmentação da membrana nuclear.

- Na metáfase II os cromossomos são alinhados na placa metafásica, enquanto na anáfase, as cromátides irmãs são puxadas para polos opostos (Figura 1-VI).

- Sendo seguida da telófase II, em que se refaz a membrana nuclear e os cromossomos descompactamse e a divisão encerra-se com a citocinese, em que o citoplasma das novas células é separado (Figura $1-\mathrm{VII})$.

Nessa simulação da meiose, serão produzidos 2 tipos de gametas, um contendo o alelo A e outro contendo o a, na mesma proporção ( $50 \%$ de cada um).

Estima-se que o tempo necessário para essa proposta lúdica seja em média 20 minutos, dependendo da turma, sugerindo-se que ocorra no dia em que o professor estiver realizando a explicação sobre a Primeira Lei de Mendel, para que os estudantes consigam relacionar o processo celular da produção de gametas que ocorre a partir da meiose, com o enunciado dessa lei. 
Figura 1. Sequência da simulação da Primeira Lei de Mendel

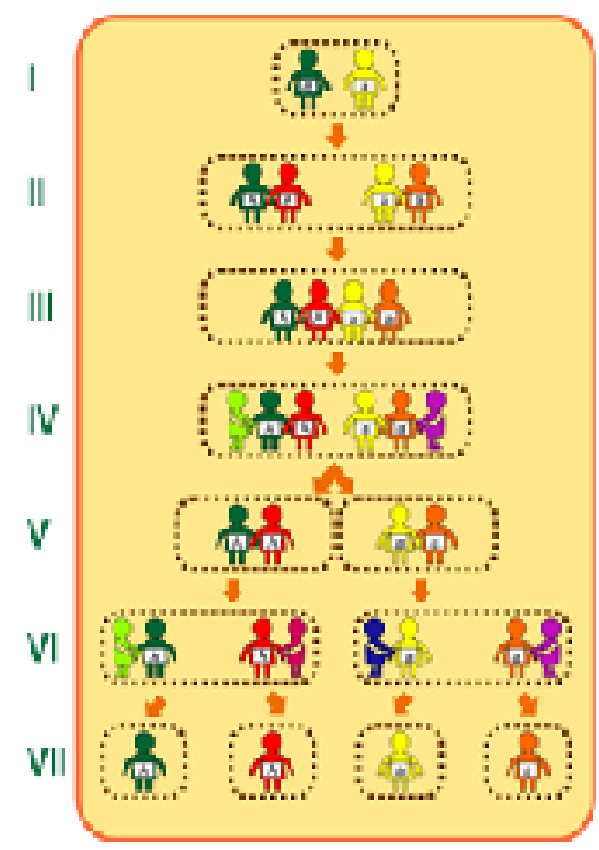

Fonte: autores

\section{- $2^{a}$ Etapa: explorando a $2^{a}$ Lei de Mendel}

\section{$2^{\mathrm{a}}$ Lei e meiose}

Na segunda Lei de Mendel (ou Princípio da Segregação Independente), ao invés de estudar uma característica por vez, vemos duas ou mais características, desde que os alelos representados não estejam em um mesmo cromossomo.

Conforme o enunciado dessa lei, na formação dos gametas, o par de fatores responsável por uma característica separa-se independentemente de outro par de fatores responsável pela determinação de outra característica. Desde que estas características sejam codificadas por alelos localizados em cromossomos diferentes, os pares de alelos localizados em cromossomos não homólogos separam-se independentemente na formação dos gametas.

E para representar isso para os estudantes e deixar os conceitos menos abstratos, sugere-se a mesma simulação anterior, só que agora com mais estudantes participantes. Representando mais um par de alelos: inicialmente 4 alunos, para representar 2 pares de alelos.

Sugerimos iniciar com dois pares de cromossomos homólogos cada um com um alelo. $\mathrm{Na}$ sequência fica a critério do professor colocar mais estudantes (cromossomos homólogos com seus respectivos alelos) (Figura 2-I).

Antes da divisão celular ocorre a interfase, também representada na $1^{\mathrm{a}}$ Lei de Mendel, em que o material genético é duplicado (8 alunos) (Figura 2-II). 


\section{Meiose I:}

- Na prófase I, ocorre o pareamento dos cromossomos homólogos e os pares de alunos que estão segurando a mesma letra, irão se aproximar (Figura 2-III). A compactação desses e a fragmentação da membrana nuclear, é narrada pelo professor.

- Na metáfase I, os cromossomos pareados são alinhados na placa metafásica, ficando os cromossomos duplicados e pareados um atrás do outro (Figura 2-IV).

- Na anáfase I outros 4 estudantes representam os fusos meióticos e separam os cromossomos duplicados (Figura 2-V), sendo que esses ainda permanecem unidos, uma cromátide irmã ligada à outra por meio do centrômero (braços dados).

- Na telófase I há descompactação dos cromossomos e regeneração da membrana nuclear, seguida da citocinese (esse fato apenas é narrado pelo professor) (Figura 2-VI).

Como a forma que os cromossomos se encontram dispostos pode variar a distribuição desses, é interessante demonstrar essas variações para que os estudantes entendam as diferentes combinações de cromossomos nos gametas, o que está representado na figura 3 pelas cores verde e lilás, demonstrando as duas possibilidades.

\section{Meiose II:}

- Na prófase II, ocorre novamente a fragmentação da membrana nuclear, e compactação dos cromossomos.

- Na metáfase II, os cromossomos são alinhados na placa metafásica.

- Na anáfase II, cada cromátide é puxada para polos opostos da célula, processo responsável por formar gametas haploides (Figura 2-VII).

- Na telófase II, refaz-se a membrana nuclear e os cromossomos sofrem descondensação (Figura 2-VIII). 
Figura 2. Sequência da simulação da Segunda Lei de Mendel

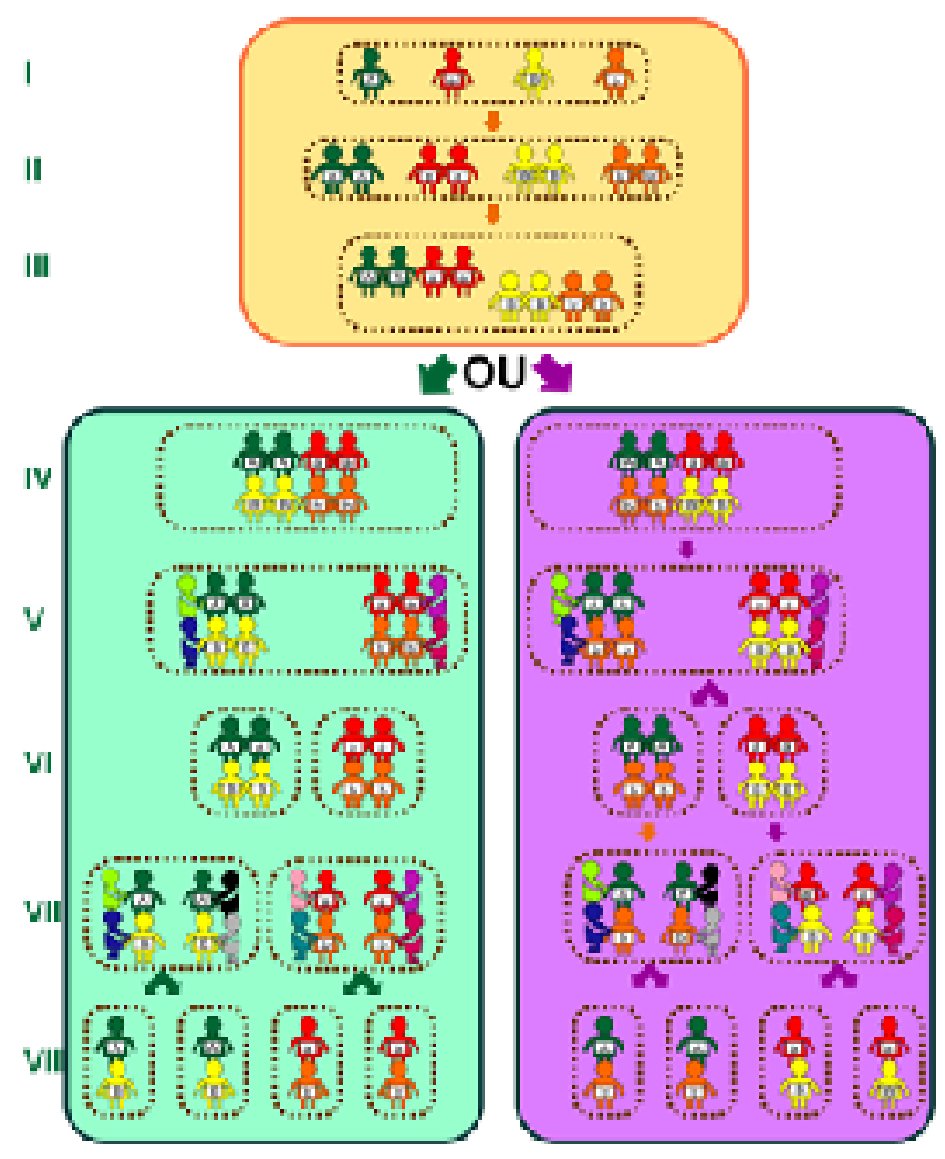

Fonte: autores

Nessa representação contendo dois pares de cromossomos homólogos, cada cromossomo com um alelo, é possível perceber a formação de 4 tipos de gametas diferentes: AB, ab, Ab, aB, que ocorrem na mesma proporção ( $25 \%$ de cada um). Estima-se que o tempo para essa simulação seja de aproximadamente uns 25 minutos, também dependendo da turma.

\section{- $3^{a}$ Etapa: explorando a Ligação Gênica}

\section{Ligação Gênica e Meiose}

Nem sempre as características são transmitidas de forma independente respeitando as proporções da $2^{\mathrm{a}}$ Lei de Mendel. Isso ocorre quando os genes estão no mesmo cromossomo, de modo que não se separam de forma independente na formação dos gametas. Quando isso ocorre dizemos que os genes estão ligados.

Na segunda Lei de Mendel, quando há dois pares de alelos, são formados 4 diferentes tipos de gametas na mesma proporção. Porém, se esses estiverem no mesmo cromossomo (ligados), há formação de dois tipos de gametas na mesma proporção, desde que não ocorra permutação. Quando 
não ocorre permutação, é denominada ligação gênica completa. Porém, se houver permutação, é chamada ligação gênica incompleta e forma-se 4 diferentes gametas em diferentes proporções, sendo que essas podem variar, dependendo da distância que os genes se encontrem no mesmo cromossomo. Quanto mais distantes, maior a probabilidade da ocorrência da permutação e maior será a taxa de gametas recombinantes. Porém, os gametas parentais ainda são originados com maior frequência.

Primeiramente, iniciamos a simulação da ligação completa ("absoluta"), sem a ocorrência da permutação (figura 3, sequência representada pela cor verde).

- Iniciamos com um par de cromossomos homólogos com genes ligados, representados por dois alunos com duas folhas coladas ao corpo, com letras desenhadas para representar dois alelos de genes diferentes no mesmo cromossomo (Figura 3-I).

- Em seguida, ocorre a preparação para a divisão celular e os cromossomos são duplicados, sendo representados por mais dois alunos (Figura 3-II).

\section{Meiose I:}

- Na prófase I ocorre a compactação dos cromossomos, a fragmentação da membrana nuclear (narrado pelo professor) e o pareamento dos cromossomos homólogos (Figura 3-III).

- Na metáfase I, os cromossomos encontram-se aos pares alinhados na placa metafásica também representado na mesma figura anterior (Figura 3-III).

- Na anáfase I (Figura 3-IV), dois outros alunos representam os fusos meióticos para separar os cromossomos e levá-los para lados opostos.

- Na telófase I (Figura 3-V) há descompactação dos cromossomos e reconstituição da membrana nuclear. Em seguida ocorre a citocinese que irá separar os citoplasmas das novas células.

\section{Meiose II:}

- Inicia-se, então a prófase II, com a fragmentação da membrana nuclear e compactação dos cromossomos.

- Na metáfase II, os cromossomos são alinhados na placa metafásica (tudo isso narrado pelo professor).

- Na anáfase II (Figura 3-VI), mais dois alunos participam como fusos meióticos, ocorrendo a separação das cromátides irmãs.

- Por fim, a telófase II (Figura 3-VII), em que irá novamente se formar a membrana nuclear e ocorrerá a descondensação dos cromossomos.

Nesse caso, como os genes encontram-se no mesmo cromossomo, há formação de apenas dois tipos de gametas diferentes $\mathbf{A B}$ e $\mathbf{a b}$, na mesma proporção, 50\% de cada um, no caso de esses alelos encontrarem-se no mesmo cromossomo. 
Porém, se houver ligação incompleta e houver permutação, representado na figura 3 pela cor lilás (Figura 3-III - lilás), simula-se na prófase I a troca de "letrinhas" entre os cromossomos que estão mais próximos no pareamento, representando trocas de pedaços entre os cromossomos homólogos. E o restante é representado da mesma forma, mas agora, há formação de 4 tipos de gametas ( $\mathbf{A B}$ e $\mathbf{a b}$ em maior proporção, pois são os parentais e Ab e aB em menor proporção, pois são os recombinantes), sendo que a proporção de cada tipo de gameta, depende da proximidade dos genes no cromossomo.

O arranjo representado na simulação, é denominado cis, em que os alelos dominantes se situam em um cromossomo e os recessivos em outro. Porém, dependendo do grau de compreensão dos alunos, pode-se começar com a célula-mãe com arranjo trans, que os genes $\mathbf{A}$ e b encontram-se em um cromossomo homólogo e a e $\mathbf{B}$ em outro.

Para essa simulação estima-se aproximadamente 30 minutos, dependendo da turma.

Figura 3. Sequência da simulação da Ligação Gênica

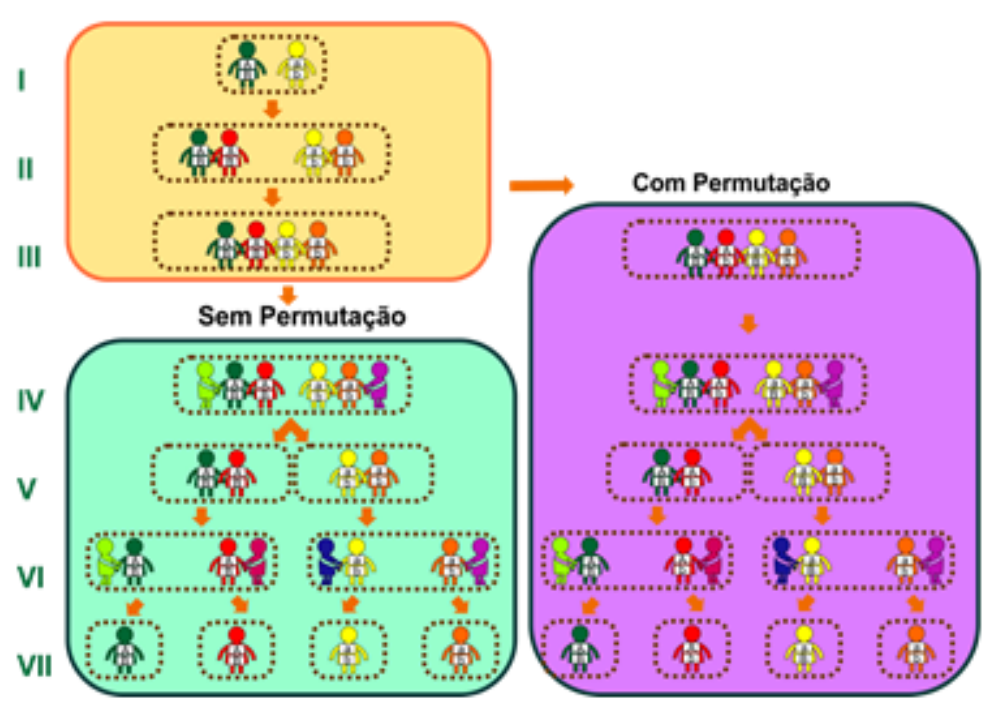

Fonte: autores

\section{- Momentos em que cada etapa dessa atividade pode ser realizada}

Sugere-se que cada uma dessas simulações seja usada ao final da explicação ou mesmo para dar apoio à exposição de cada conteúdo. E que após todos os conteúdos trabalhados $\left(1^{\mathrm{a}}\right.$ Lei, $2^{\mathrm{a}}$ Lei e Ligação Gênica), as três simulações sejam realizadas novamente, em uma única aula, para que os estudantes percebam a integração desses conteúdos. É necessário aproximadamente uma aula de 50 minutos para relacionar os temas estudados. 


\section{RESULTADOS E DISCUSSÕES}

Essa atividade lúdica é uma proposta didática para auxiliar professores a fazer com que seus estudantes compreendam que a transmissão das características hereditárias é possível devido aos processos de divisão celular para formação dos gametas e posteriormente, à fecundação.

A estratégia didática foi planejada para ser de baixo custo, para que pudesse ser realizada com estudantes da rede pública quanto de privada. Teve sua viabilidade testada com estudantes de ensino médio de uma rede privada de ensino de Curitiba, com estudantes de dois colégios da rede Estadual da área Metropolitana Sul de Curitiba, com estudantes de graduação dos cursos de Biomedicina, Biologia e Zootecnia matriculados na disciplina de Genética da Universidade Federal do Paraná. E passou a compor uma Oficina de extensão para formação continuada de professores da educação básica denominada Desenrolando a Genética. Compondo uma tese de doutorado relacionada à produção de estratégias didáticas para o Ensino de Genética.

$\mathrm{Na}$ oficina para docentes foi utilizado também massinha de modelar representando os cromossomos para recordar a meiose, permitindo também a compreensão das quantidades de DNA em cada etapa da divisão. Propondo aos docentes mais uma forma de auxiliar seus estudantes para recordar a meiose, antes da aplicação dessa atividade.

É importante que o professor não se atenha apenas ao uso do livro didático. Pois mesmo na carência de equipamentos sofisticados, é possível realizar atividades simples e que atendam ao objetivo da aula (JUSTINA e FERLA, 2006).

Em estudos realizados por Fabrício (2005) com estudantes do ensino médio e ensino superior de licenciatura de biologia, foram verificadas dificuldades nos dois níveis de ensino no que se refere aos conceitos básicos de genética, sob a alegação de faltavam conhecimentos prévios a respeito do assunto, alguns demonstraram conhecimento falho ou desconexo e mesmo os que afirmavam não ter dificuldades, apresentaram altos índices de erro, o que é ainda mais preocupante. As perguntas respondidas por eles tinham o objetivo de verificar seus conhecimentos quanto à Primeira Lei de Mendel, se compreendiam como ocorre a transmissão das características hereditárias, além de conhecimentos básicos como genótipo, fenótipo, genes, alelos e formação de gametas. Foi verificado pelo autor que tanto estudantes do ensino médio quanto do ensino superior possuíam dificuldades. $\mathrm{O}$ que é preocupante, já que os licenciandos em Biologia seriam os futuros professores a ministrar aulas sobre esses assuntos. Um docente não pode se permitir dominar apenas alguns conteúdos da sua área de conhecimento.

\section{CONSIDERAÇÕES}

A contribuição da estratégia didática exposta para o processo de ensino-aprendizagem dos objetos de conhecimentos relacionados à genética, consiste na incorporação de uma atividade que se baseia na ação. Buscando uma linguagem diferenciada para demonstrar as relações nem sempre 
percebidas quando explicadas em uma aula expositiva isolada. Nesse contexto, é oportunizada uma forma de compreender as proposições subjacentes à Ligação Gênica, à $1^{\mathrm{a}} \mathrm{e}$ à $2^{\mathrm{a}}$ Leis de Mendel de forma integrada e como resultado de mecanismos relacionados à meiose. Além de uma compreensão cromossômica e celular que possibilita a variabilidade genética por meio da reprodução sexuada.

Sendo estimulada uma aprendizagem pautada na compreensão de processos biológicos e não por memorização apenas.

\section{REFERÊNCIAS}

AUSUBEL, David. A cognitive structure view of word and concept meaning. In: ANDERSON, Richard; AUSUBEL, David (Ed.). Readings in the Psychology of Cognition. 1.ed. New York. Holt, Rinehart \& Winston. p.58-75, 1965.

CAMPOS, Luciana Maria Lunardi; BORTOLOTO, T. M; FELÍCIO, A. K. C. A produção de jogos didáticos para o ensino de ciências e biologia: uma proposta para favorecer a aprendizagem. Caderno dos núcleos de Ensino, v. 47, p. 47-60, 2003.

CID, Marília.; NETO, Antônio. J. Dificuldades de aprendizagem e conhecimento pedagógico do conteúdo: o caso da genética. In: Enseñanza de las ciencias, Barcelona, n.extra, p. 1-5, nov. 2005. VII Congreso sobre Investigación en la didáctica de las ciencias.

GARDNER, Howard. Inteligências Múltiplas: a teoria na prática 1. ed. Porto Alegre: Editora Artes Médicas. 1995.

JUSTINA, Lourdes Aparecida Della; RIPPEL, Jorge Luiz. Ensino de genética: representação da ciência da hereditariedade no nível médio. IV Encontro Nacional de Pesquisa em Educação em Ciências. Cascavel. Paraná. 2003.

LEWIS, Jenny; LEACH, John; WOOD-ROBINSON, Colin. What's a cell? - young people's understanding of the genetic relationship between cells, within an individual. Journal of Biological Education, v. 34, n.3, p. 129-132, 2000.

HERMANN, Fabiana Barrichello; ARAÚJO, Maria Cristina Pansera. Os jogos didáticos no ensino de genética como estratégias partilhadas nos artigos da Revista Genética na Escola. VI Encontro Regional Sul de Ensino de Biologia (EREBIO-SUL) Rio Grande do Sul, 2013.

MANZKE, Vítor Hugo Borba. Aspectos da interação entre o professor de biologia e o livro didático no ensino de genética, na cidade de Pelotas, RS. Florianópolis, SC.1999.

MOREIRA, Marco Antonio. Aprendizaje significativo: teoria y práctica. VISOR. Madrid, 2000.

TRAVASSOS, Luiz Carlos Panisset. Inteligências Múltiplas. Revista de Biologia e Ciências da Terra, v. 1, n. 2. 2001. 
WOOD-ROBINSON, Colin; LEWIS, Jenny \& LEACH, John. Young people's understanding of the nature of genetic information in the cells of an organism. Journal of Biological Education, v.35, n.1, p. 29-36, 2000. 


\section{ÍNDICE REMISSIVO}

\section{Símbolos}

$1^{\mathrm{a}}$ e $2^{\mathrm{a}}$ Lei de Mendel 114,116

A

alelos 98, 99, 100, 101, 102, 105, 107, 108, 110, 117, 118, 119, 121, 122, 123, 124

alfabetização científica 42, 44, 51, 61, 62

alginato $42,44,45,46,48,52,53,55,56,57,59,64$

alginato de sódio 42, 44, 45, 46, 53, 56, 57

ambiente escolar $13,29,53,55,58,89$

animais nativos $76,80,84$

animais vertebrados $76,77,78,83$

animais vertebrados e o ser humano 76

Aprendizagem 18, 65, 67, 112

aprendizagem de biologia 114

atividade experimental $44,45,46,53,55,56,58,62$

atividades remotas 11,15

aulas de biologia 28

aulas presenciais $11,15,17,89,90$

aulas remotas 11,13

a vida em sociedade 127

B

Biologia $6,11,14,15,16,17,20,22,24,26,27,37,40,41,63,85,86,88,100,110,112,115,116,124,125,133$

biologia celular 114,115

botânica 65,70

C

campo da ecologia 65,69

campo da nanotecnologia 53,62

caráter histórico e dinâmico da ciência $\square 28,36,37$

carreadores de fármacos $42,43,44$

cátions bivalentes 53,55

ciclo da doença $20,22,23$

ciência como atividade coletiva $\square 28,36,37,38$

Ciências $11,12,14,15,16,18,22,24,26,40,41,43,44,48,50,62,65,67,75,87,91,110,111,112,117,125,137$ 
citologia $37,65,70$

compreensão e fixação das informações 19

comunidade $20,22,25,76,77,78$

conceito de homofobia 127,134

concentração nos estudos 11, 15

conexão de internet 11

conhecimentos da genética 114

consciência biológica 76, 84

construção de cordéis 65,67

conteúdo didático 11,12

conteúdo informativo 20

cromossomos $98,99,100,101,102,104,105,106,108,109,110,114,115,117,118,119,120,121,122,123,124$

$\mathbf{D}$

Dança dos Cromossomos 114, 116

déficit informativo 19

didáticas alternativas 98

dificuldade de entender os conceitos 11

dificuldade na compreensão 97

Dificuldades de aprendizagem 11, 111, 125

dificuldades do aprendizado 11

dinâmica das aulas 87,88

disciplina de genética 97, 115

dispositivo eletrônico 11, 16

disseminação de conhecimento 20, 21

diversidade $71,77,127,132$

doenças negligenciadas 19

dominância completa 98, 100

E

Educação básica 11

educação sexual 127,135

Enfrentamento das visões ingênuas sobre a ciência 28

ensino da hereditariedade 97

ensino de ciências $27,28,32,40,42,51,96,125$ 
ensino de parasitologia 19,22

ensino remoto $11,13,14,17,87,88,89,90,91,92,96$

entendimento sobre a amebíase 20

esferas de alginato $42,45,46,47,48,53,56,57,58,59,60$

espécie humana 77, 101

espermatozoides 98, 100, 102, 107, 108, 109

Estratégias 26, 63, 65

estudantes de biologia 98

Estudos Culturais em Educação 127, 128

estudos histórico-filosóficos 28

etapa experimental 53

F

falta de reflexão sobre a $\mathrm{NdC} 28$

família 76, 80, 136

farmacocinética 42,50

fármacos $42,50,55$

fechamento das escolas 11,12

fenômeno biológico 101, 108, 113, 115

fenômenos biológicos 114

fenótipo 98, 100, 103, 108, 124

ferramenta didática $65,67,114$

ferramenta didática adjuvante 65

fisiologia humana 87, 91, 94

formação dos gametas 114, 117, 118, 119, 121, 124

formato de aprendizagem 11

formulação convencional 42

fusos meióticos 114, 120, 122

G

genótipo 98, 100, 101, 102, 124

graduação nas áreas biológicas 98

H

hereditariedade $98,99,101,110,111,112,113,114,115,125,133$

homem e natureza $76,77,82,84$ 
homem e natureza/vertebrados 76

homem primitivo 76,77

homossexualidade 127, 128, 129, 130, 131, 132, 133, 134, 135, 136, 137

I

Inclusão 11

inteligência cinestésico-corporal 114, 116

interdisciplinaridade 42,50

interesse em aprender 87, 95

J

jovens em idade escolar 11

$\mathbf{L}$

Leis de Mendel 110, 113, 114, 115, 125

Ligação Gênica 114, 116, 121, 123, 125

linguagem e conceitos complexos 19,21

lipossomas 42,44

Literatura $65,74,75$

literatura de cordel $65,66,67,68,73,74,75$

livro paradidático de sexualidade 127, 128, 129, 131, 132

livros didáticos $28,31,32,33,34,35,36,38,39,41,48$

livros didáticos de biologia $28,31,32,34,35,36,38,41$

livros didáticos de ciências/biologia 28

M

manifestações culturais 65,66

materiais didáticos 14, 20, 22, 25, 31, 52, 62, 63

materiais poliméricos 53

mecanismos biológicos 113

medicamentos $42,43,44,58$

meio ambiente $65,69,77,78$

meiose $71,101,114,116,117,118,119,124,125$

Mentimeter 87, 88, 89, 92

Metodologias 14, 18, 65, 95, 96

metodologias ativas $14,87,89,90,91,94,96$

métodos profiláticos 20 
microestruturas 53,55

minimizar prejuízos 11

Ministério da Educação 11, 88

Ministério da Saúde 11

modelos didáticos 24, 98,100

modo de transmissão 20,22

mudanças no âmbito educacional 87, 88

$\mathbf{N}$

nano- e micropartículas 42

nanosistemas 42

nanotecnologia $43,50,53,54,55,56,57,58,61,62,63,64$

nanotecnologia e suas aplicações 54, 57, 62

natureza da ciência (NdC) 28, 29

novo coronavírus 87,88

O

oficinas de versificação 65

$\mathbf{P}$

Padlet 87, 88, 89, 92, 93

padrões de herança 98, 100, 101, 103, 110, 111

pandemia $11,12,14,17,18,87,88,89,96$

pandemia do COVID-19 11, 14

panfletos informativos 20

participação ativa $14,62,87,91,92,93,94,95$

participação mais efetiva 43, 44, 51, 62

Pecha Kucha 87, 88, 89, 90, 91, 92, 93

perspectiva cidadã 127

perspectiva sociocultural 127

plataformas digitais 11,15

polissacarídeo natural 44, 53, 55

poluição $55,65,69,70,82$

povo nordestino 65

principais dificuldades 11

problematização 28, 129, 134 
processo da fecundação 98,101

processo de ensino-aprendizagem 20, 25, 39, 52, 87, 100, 115, 124

professor de biologia 114,125

protozoário Entamoeba histolytica 20, 21

R

recursos didáticos alternativos 19,100

relação ecossistêmica 76,80

responsabilidade com o ambiente 76,84

$\mathbf{S}$

segurança $11,12,81$

simulações 98, 123

sobrevivência $76,78,79,80,83$

subsistência $76,77,79,80,82,83,84$

sub terapêutica 42

suspensão das aulas presenciais 11

sustentabilidade $65,69,71$

T

Tecnologias Digitais de Informação e Comunicação (TDICs) 87, 89

teoria celular $28,31,32,37,38$

terapêutica 42,49

Trilha da aprendizagem $87,89,90,92$

$\mathrm{U}$

uso de jogos 98

V

vírus SARS-CoV-2 11,12

$\mathbf{Z}$

zoologia 65,70 
